\title{
Biodiversity data obsolescence and land uses changes
}

\author{
Nora Escribano ${ }^{\text {Corresp.., }}{ }^{\text {, }}$, Arturo H Ariño ${ }^{1}$, David Galicia ${ }^{1}$ \\ ${ }^{1}$ Department of Environmental Biology, Universidad de Navarra, Pamplona, Spain \\ Corresponding Author: Nora Escribano \\ Email address: nescribano@alumni.unav.es
}

Background. Primary biodiversity records (PBR) are essential in many areas of scientific research as they document the biodiversity through time and space. However, concerns about PBR quality and fitness-for-use have grown, especially as derived from taxonomical, geographical and sampling effort biases. Nonetheless, the temporal bias stemming from data ageing has received less attention. We examine the effect of changes in land use in the information currentness, and therefore data obsolescence, in biodiversity databases.

Methods. We created maps of land use changes for three periods (1956-1985, 1985-2000 and 2000-2012) at 5-kilometres resolution. For each cell we calculated the percentage of land use change within each period. We then overlaid distribution data about small mammals, and classified each data as 'non-obsolete or 'obsolete' depending on both the amount of land use changes in the cell, and whether changes occurred at or after the data sampling's date. Results. 14,528 records out of the initial 59,677 resulted non-obsolete after taking into account the changes in the land uses in Navarra. These obsolete data existed in 115 of the 156 cells analysed. Furthermore, more than one half of the remaining cells holding non-obsolete records have not been revisited at least for the last fifteen years. Conclusion. Land use changes challenge the actual information obtainable from biodiversity datasets and therefore its potential uses. With the passage of time, one can expect a steady increase in the availability and use of biological records-but not without them becoming older and likely to be obsolete by land uses changes. Therefore, it becomes necessary to assess records' obsolescence, as it may jeopardize the knowledge and perception of biodiversity patterns. 


\section{Biodiversity data obsolescence and land use changes}

2 Nora Escribano ${ }^{1}$, Arturo H. Ariño ${ }^{1}$, David Galicia ${ }^{1}$

3 1. Universidad de Navarra, Facultad de Ciencias, Department of Environmental Biology,

4 Campus Universitario, 31080, Pamplona, Spain

5 Corresponding author

6 Nora Escribano

7 Email address: nescribano@alumni.unav.es 
9 Abstract

10 Background. Primary biodiversity records (PBR) are essential in many areas of scientific research as they document the biodiversity through time and space. However, concerns about PBR quality and fitness-for-use have grown, especially as derived from taxonomical, geographical and sampling effort biases. Nonetheless, the temporal bias stemming from data ageing has received less attention. We examine the effect of changes in land use in the information currentness, and therefore data obsolescence, in biodiversity databases.

Methods. We created maps of land use changes for three periods (1956-1985, 1985-2000 and 2000-2012) at 5-kilometres resolution. For each cell we calculated the percentage of land use change within each period. We then overlaid distribution data about small mammals, and classified each data as 'non-obsolete or 'obsolete' depending on both the amount of land use changes in the cell, and whether changes occurred at or after the data sampling's date.

Results. 14,528 records out of the initial 59,677 resulted non-obsolete after taking into account the changes in the land uses in Navarra. These obsolete data existed in 115 of the 156 cells analysed. Furthermore, more than one half of the remaining cells holding non-obsolete records have not been revisited at least for the last fifteen years.

Conclusion. Land use changes challenge the actual information obtainable from biodiversity datasets and therefore its potential uses. With the passage of time, one can expect a steady increase in the availability and use of biological records - but not without them becoming older and likely to be obsolete by land uses changes. Therefore, it becomes necessary to assess records' obsolescence, as it may jeopardize the knowledge and perception of biodiversity patterns. 
31

32

\section{Introduction}

Primary biodiversity records (PBR) are essential in biogeography, trend assessment, climate change ecology or conservation biology (Rocchini et al., 2011; Powney \& Isaac, 2015). At their most basic, PBR provide fundamental data about location of living beings - what, where and when- (Ariño et al., 2012) and have been widely used for building maps and models of species distribution.

Interest in this type of data, which provides direct information about where organisms have been previously reported, has grown in recent years as the loss of biodiversity has become one of the main concerns in the scientific community (Hermoso, Kennard \& Linke, 2013). The relevance and the utility of these data are both important for assessing priority areas for conservation and determining drivers of biodiversity loss (Willis et al., 2007; Powney \& Isaac, 2015, CBD, 2010). Free access to PBR has been steadily increasing in the last decade as many initiatives of data sharing have been launched (e.g. GBIF, VerNet, Living Planet Index). However, concerns about the quality and fitness-for-use of this data have grown since massive biodiversity data have become available (Hill et al., 2010; Ariño, Chavan \& Fatih, 2013; Faith et al., 2013). The quality of data responds to different sources of errors and uncertainties, and these determine their usability. Typically, information in datasets is spatially and taxonomically biased and differs in the amount of sampling effort (Boakes et al., 2010) so researches have focused on addressing which roles play these limitations on data quality (Sastre \& Lobo, 2009; Otegui et al., 2013; Beck et al., 2014). All of this has led to important research articles and guidelines about how to avoid and reduce data uncertainty (e.g. Chapman, 2005).

Nevertheless, researchers have paid less attention to temporal bias. By definition, a PBR is always a piece of information about the past (where and when an organism was recorded). Thus, 
54 its usefulness for estimating current ecological phenomena (like distribution or niche preference)

55 will be affected by its age. As time goes by and the PBR becomes older, uncertainty about its

56 spatial information is expected to increase. Obviously, the population may have gone extinct

57 locally and thus, we cannot assure that, at the present, the PBR is informative about if the

58 population still spreads there. However, it is also worth noticing that the habitat present at the

59 locality may have changed since the species was recorded and thus, any matching between

60 specimen location and habitat conditions must assure the temporal synchrony of both aspects of

61 the species' ecology. Comparatively, while information about locations of individuals in the past

62 is abundant, information about past conditions of the territory (e.g. land uses) is not as common.

63 As this temporal gap grows, we cannot guarantee that the current environmental conditions

64 resemble those when the observation or specie was recorded. We may thus expect this

65 uncertainty to eventually reach some threshold value that would turn it into an outdated PBR,

66 unsuitable for being used in models under current habitat conditions. In this way, we use the term

67 obsolete to define a PBR whose temporal frame no longer supports the relationship between

68 referred specimen and current habitat conditions. In many cases, the uncertainty of older records

69 has led to include only recent ones in studies about distribution patterns or niche modelling

70 (Moscoso, Albernaz \& Salomão, 2013; Ficetola et al., 2014). But, as far as we know, the

71 expiration of the records has not been assessed in literature.

72 At short (e.g. intra-successional) time scales, communities tend to show a characteristic

73 composition as long as habitat conditions remain stable. Their persistence will vary according to

74 multiple factors, like their ecological structure and species' natural history (Pimm, 1991), but

75 ecosystem alterations may induce permanent changes in communities. Thus, the uncertainty

76 about the presence of some species will be higher in ecosystems that have undergone 
77 modifications between the time of record and the time of record's usage. And as land use changes, biological invasions and other causes of rapid diversity loss proceed (Sala et al., 2000; Crowl et al., 2008), obsolescence could become even more a crucial factor. Humans have a large trajectory of changing landscapes, being one of the most highlighted drivers of biodiversity loss (Ellis et al., 2010). Recent studies have shown the direct relation between the changes in the use of land and changes in bird (Rittenhouse et al., 2012; Dorresteijn et al., 2015), mammal (Sieber et al., 2015; Torre et al., 2015; Cisneros, Fagan \& Willig, 2015), amphibian (Nori et al., 2015) and invertebrate communities (Ngai et al., 2008; Wagner, Krauss \& Steffan-Dewenter, 2013). Therefore, when the dates of records in a biodiversity database coincide with, or precede, important changes in land use, neglecting obsolescence of the data could allow for a considerable amount of noise in the primary data used to estimate potential distribution areas or diversity patterns.

In this paper we investigate the effect of changes in land use on the obsolescence of data contained in biodiversity databases. For this purpose, it is necessary long term biodiversity data from an area where changes in the territory have occurred but also that this geographical information is accessible or even exists. These two requirements are met in the Vertebrate Collection of the Museum of Zoology of University of Navarra (hereafter MZNA) which holds mammal's long term data from the state province of Navarra. Moreover, the geographic information system of Navarra (SITNA) gathers land uses information covering the temporal data frame of the MZNA dataset. Thus, this study extent together with the rich data from mammals in this area makes it a valuable testing ground for the target of this research.

2. Materials and methods 2.1. Study region 
100 Navarra is a $10,391 \mathrm{~km}$ square region located in the north of Spain, wedged between the western 101 end of the Pyrenean Range and the Ebro Basin (Fig. 1). Both Eurosiberian and Mediterranean 102 bioregions occur in this territory. It gathers a high landscape diversity as a result of its wide 103 variety of climatic and topographic conditions (Nogués-Bravo, 2006). The northern areas, with 104 mean altitudes above 800 metres (range $200 \mathrm{~m}-2000 \mathrm{~m})$, high precipitations $(1200-1700 \mathrm{~mm}$ of 105 mean annual rain and snowfall) and moderate temperatures, are covered by pastures and natural 106 beech and oak forests as well as pine plantations. Agricultural and Mediterranean landscapes 107 dominate the south of Navarra, with mean altitudes below 400m and a combination of low 108 precipitation (below 400mm) and temperature that favour the presence of rich communities of xerophytic shrublands. All this variety of habitats determines the high diversity of the small 110 mammals' community in Navarra, which comprises 31 of the 34 species of native insectivorous 111 and rodents cited in the Iberian Peninsula (Escala et al., 1997).

112 2.2. Biodiversity data

113 Data about small mammals for the region were extracted from the Pellet sampling dataset

114 (Escribano et al., 2016) from the Vertebrate Collection of the Museum of Zoology of the 115 University of Navarra. This dataset includes information of small mammals' records obtained 116 from the analysis of barn owl's pellets and comprises $75 \%$ of the Collection in a time range 117 spanning from 1967 to 2011 . At this moment, the dataset constitutes the best comprehensive, 118 publicly accessible collection of small mammals in Spain (Fig. 1 and Fig. 2A). As pellets have 119 proved to be very useful for assessing the small mammals' community in a territory (Torre, 120 Arrizabalaga \& Flaquer, 2004; Avenant, 2005), this dataset is a valuable tool for analysing the 121 changes in distribution patterns of diversity in the last four decades. 
122 In order to avoid overestimating the abundance of individuals, only record from skull remains

123 where selected for analyses. Records from species rarely predated by barn owl or records lacking

124 in coordinates and date of the sampling event were also discarded. In total, 59,677 records of 27

125 species of small mammals were used for the study (see Table S1).

$126 \quad 2.3$. Land use data

127 Land use data was obtained from the Geographic Information System of Navarra. For our 128 purpose, we chose the land use maps for 1956, 1985, 2000 and 2012 covering the entire time 129 span in our occurrence data. All maps are polygon-based layers that provide information about 130 land cover types in Navarra.

131 We reclassified the land uses categories into five new categories attending to the structure of the

132 vegetation cover: forest, bushes and meadows, herbaceous crops, woody crops and unproductive 133 areas. In order to standardize the polygon's information and allow the later comparison of the 134 different maps, each polygon was summarized by a relative abundance matrix of the five new 135 categories considered. In this way, homogeneous polygons were expressed as matrices with a 136 value of 1 in the appropriate category and 0 in the rest, while mixed polygons showed the 137 proportional values for each category (that together equal the unit). For further details on the 138 standardization of the maps see Document S1.

139 2.4. Land use changes and biological data analysis

140 We used ArcGIS 10 software to perform spatial analyses (ESRI, 2015). We calculated the land 141 uses changes for the three periods delimited by the reference maps (1956-1985, 1985-2000 and 142 2000-2012) by means of a spatial intersection of the corresponding maps. The three resultant 143 maps of land use changes consisted on a series of polygons that either (1) had not suffered from 144 changes in their land uses (there were not changes in their relative abundance matrices) or (2) 
145 had change from one land use to another (their relative abundance matrices were different). A

$1465 \times 5 \mathrm{~km}$ grid was then superimposed to the study area, summarizing the percentage of land use

147 changes per cell by dissolving all their polygons (see Document S1). The spatial resolution of the

148 study $(25 \mathrm{~km} \mathrm{sq})$ was set accordingly to the assumed home range of the barn owl as the mammals'

149 records come from pellets of this bird. A radius of $3 \mathrm{~km}$ from the nest/roosting site (and then an

150 ideal circular area of about $28 \mathrm{~km} \mathrm{sq}$ ) is accepted to be suitable to characterize the habitat of this

151 predator in a territory (Martínez \& Zuberogoitia, 2004). The small mammals' records were also

152 collapsed to the same grid. Cells with no recorded occurrences as well as those with an effective

153 size below $12.5 \mathrm{~km} \mathrm{sq}$ (mostly located in the border of the study area) were discarded.

154 In order to evaluate the records' obsolescence, cells with more of the $25 \%$ of their surface

155 affected by land use modifications were labelled as highly modified cell (HMC). The threshold

156 was empirically established based on those cells with sampling series long enough to perform

157 comparative analyses of community and territorial changes (see Document S1 for further details).

158 Then, following the reasoning presented previously, samples collected before or during periods

159 of land use changes were labelled as obsolete.

160 3. Results

161 3.1. Temporal variation in data sources

162 Our analysis of the net changes in the land uses of Navarra showed that $27 \%$ of its surface has 163 changed during the entire dataset's timeframe (1956-2012). Overall, forestry land uses increased

164 by $11 \%$ while meadows and shrublands decreased by $12 \%$. Herbaceous and woody crops

165 suffered a small decrease, and unproductive areas increased slightly. Relative to HMC, we found 166 that they were greater in the periods 1956-1985 and 1985-2000 representing more than the $60 \%$ 
167 of cells. On the contrary, between 2000 and 2012 the number of HMCs decreased and there were 168 only 14 HMC.

169 After discarding records from species rarely preyed upon by the barn owl and records that did 170 not come from the study area, the dataset provided 59,677 georeferenced records of 27 species of 171 small mammals. Despite the relatively large number of records in a relatively small area, little 172 more than one third of the cells held data $(36.02 \%, 156$ cells $)$. Also, the temporal distribution of 173 records from 1966 to 2011 showed an evidently clumped pattern, with a main sampling period 174 centred on the 80's (Fig. 2A). This period corresponds with the years leading to the publication 175 of a regional atlas about the insectivorous and rodents community (Escala et al., 1997). Although 176 most of the sampling effort was made between 1987 and 1992 (more than 55\% of the records 177 come from those years), we can observe another period where records from pellets increased 178 between 1980 and 1987 . This inventorying was not large in terms of occurrences, but was 179 remarkably uniform through time. After the publication of the atlas, addition of new records of 180 small mammals decreased.

181 Regarding to the richness of the dataset, all the 27 species considered in this study were already 182 present in the database by 1991 and richness had almost attained a plateau five years before (Fig. 183 2A). Even though samples collected after 1985 did not contribute significantly to the total 184 richness of the group, the spatial representativeness of the dataset grew considerably (Fig. 2B). 185 The sampled area duplicated from 1985 to 2000, adding 91 new cells, previously unsampled, and 186 thus increasing the biogeographical information of most of the species.

187 3.2. Obsolescence analysis

188115 of the 156 cells analysed $(73.72 \%)$ contained obsolete data, that is, some of the samplings 189 were performed before or during periods when the land use changed. If we exclude these 
190 outdated occurrences, the dataset information fells down to 14,528 records belonging to 24

191 species. Although cells holding these non-obsolete records have not suffered from considerable

192 land use changes $(<25 \%$ of its surface changed) ever since samplings occurred, more than one-

193 half of these cells were not visited again over the last fifteen years (Fig. 3).

194 Species by species, the overall attrition rate (number of records filtered out by flagging them as

195 obsolete) was generally high, over $70 \%$ in $74 \%$ of the species. The information loss was critical

196 in species with very low representation in the original dataset, such as Crocidura suaveolens

197 Pallas, 1811, Microtus cabrerae (Thomas, 1906) and Sorex araneus Linnaeus, 1758. Although

198 an overall reduction in record numbers is expected to affect all species to a greater or lesser

199 extent, these species actually disappeared from the dataset (Table 1).

200 4. Discussion

201 4.1. Biodiversity records in a changing territory

202 The land use analysis showed a generalized increase in forested surface along the considered

203 time, while meadows and shrublands show the opposite tendency. These two changes occurred

204 mainly in the earliest period (from 1956 to 1985). The reduction of meadow land seemed related

205 to an increase in forest cover due mainly to two managerial practices: (1) steady repopulation on

206 bare soils with tree species as an erosion-avoiding strategy, and (2) phasing out of fuel in favour

207 of other energy sources, which occurred mainly between 1970 and 1990 (Gobierno de Navarra,

208 2000; Nogués-Bravo, 2006). However, our study does not aim to understand how Navarra has

209 shifted its landscape, but to record the main land use changes at the sites where small mammals

210 were recorded. These changes might therefore compromise the information that could be

211 obtained from the biodiversity datasets. 
212 We found that more than half the record-bearing territory area contained records compromised

213 by such changes, and thus potentially obsolete records. After applying our criterion of filtering

214 out PBR collected before or during land use changes, we discarded approximately $75 \%$ of the

215 small mammals' records (Fig. 4). As reported in several studies, changes in the management of

216 the territory have led to changes in communities and older records may not reflect the current

217 communities. For example, Torre et al. (2015) resampled historically sampling sites for barn owl

218 pellets finding changes in the frequencies of small mammals and a decrease in the species

219 richness from 14 to 10 . Similarly, when we discarded data compromised by land use changes,

220 richness in our 'Pellet sampling' dataset lost three of the rarest species. Furthermore, the number

221 of cells in which each species was recorded was reduced in most cases by more than $70 \%$. The

222 loss of information was not concentrated at specific sites, but spread all over the studied territory.

223 4.2. Implications of data obsolescence

224 Obsolescence could become a critical factor for species whose distribution pattern remains

225 unclear. For example, M. cabrerae is an endemism of the Iberian peninsula, but its distribution is

226 still unclear as information about its presence is patchy (Garrido-García et al., 2013). This

227 knowledge gap ushered this microtine into the UICN Red List as 'Nearly Threatened' (see Table

228 S1) and catalogued as 'Vulnerable' in Spain (Palomo, Gisbert \& Blanco, 2007). But if the data

229 records of this species are old enough and come from a territory where land use changes have

230 occurred afterwards, we cannot longer guarantee that those records are contributing to a reliable,

231 current picture of its actual distribution. Similarly, other species whose distribution is unknown

232 will suffer from the same lack of confidence.

233 Obsolescence could also affect the outcomes of SDMs when the habitat descriptors do not match

234 the data frame of the biodiversity records used to calibrate the model, thus giving a biased result. 
235 The main challenge is then to find a way of estimating how much this ageing in relation to a

236 desired timeframe, e.g. the 'now', may affect the outcome of the model. As PBR are central to

237 the construction of these models, it is important to considerate this limitation as well as other

238 types of biases.

239 On the contrary, by highlighting the obsolete information of a dataset we can identify which

240 parts of the territory are not appropriately sampled according to the recent history of human

241 interventions in the area. These areas can then be targeted for surveying. Due to the current

242 budget limitations for inventorying and completing databases with new records, it is imperative

243 to design suitable surveys (Sánchez-Fernández et al., 2011) and monitoring programs (Boero et

244 al., 2015) that optimize the available resources into a significant increase of biodiversity

245 information. Our results showed that records from abundant species are prone to a lower

246 decrease whereas records from rare species show a greater rate of attrition. Together, these two

247 observations can help guide sampling efforts towards more efficient campaigns that may close

248 knowledge gaps (Ariño, Chavan \& Otegui, 2016). It might thus be preferable, and accrue more

249 information, to sample those cells were rare species are distributed, where records are old, and

250 where changes in land use have occurred since the locality was last sampled. This would

251 improve survey designs and efficiently monitoring wildlife, returning maximum information

252 while spending minimum sampling efforts.

253 However, as we have only considered just one factor affecting obsolescence of the data -land use

254 changes- our results should be interpreted with caution. Other elements should be explored that

255 might be likely playing a role in the obsolescence of data. For example, changes in land uses can

256 affect species differently according to their life histories (De Palma et al., 2015) and, therefore,

257 the biology of a species could likely be a factor affecting obsolescence. 
258 In this study we have explore the obsolescence of biodiversity records related to the land uses

259 changes. We have pointed out that these records can be outdated and might give us an out-of-

260 time picture of species distribution. However, we have only scratched the surface and we still

261 have to explore in depth the implications of obsolescence of data and whether the use of obsolete

262 data can be misleading towards understanding current species distribution patterns.

263 5. Conclusion

264 As time goes by, we can expect to observe a steady increase in the availability and use of

265 biological records but by definition, records taken at a fixed point in time will age: their validity

266 or fitness-for-use may decrease as the gap between their recording time and their application

267 time increases. Continuing digitization and release of data from museums or private collections,

268 which may likely include old records, will increase the need to determine, and account for,

269 obsolescence of those records as its age could compromise the knowledge and perception of

270 current distributional patterns of biodiversity worldwide.

271 In geographical terms, we have tested a relatively local dataset. However, we believe that our

272 observations could be generalized to other cases and other extents. Land uses changes have been

273 recorded from regional to global scales (Feranec et al., 2010; Ellis et al., 2010) and databases

274 seem to share the same limitations of spatial, taxonomical and temporal biases (Sastre \& Lobo,

275 2009; Boakes et al., 2010; Isaac \& Pocock, 2015). Although we could not find literature to

276 compare our results to other similar analyses, we can expect that our findings within the MZNA

277 database in Navarra can be reproduced in other databases as well.

278 6. Acknowledgements

279 We are very grateful to Dr Carmen Escala who started to document the small mammals'

280 community of Navarra in the department of Environmental Biology of University of Navarra 
281 actively contributing to the creation of the 'Pellet sampling' dataset from the MZNA. Without

282 her effort and dedication of inventorying the small mammals' community, we could not have

283 done this research. We also thank all researches, technicians and volunteers that contributed with

284 information to the dataset. Finally, we acknowledge two anonymous reviewers for valuable

285 comments that improve considerably the manuscript.

286 7. Data accessibility

287 All biological records of small mammals are freely available through GBIF portal. We used the 2882.4 version of this dataset.

289 DOI:10.15470/qomfu6

290 8. REFERENCES

291 Ariño AH., Otegui J., Villarroya A., Zabalza AP De. 2012. Primary Biodiversity Data Records in 292 the Pyrenees. Environmental Engineering and Management Journal 11:1059-1075.

293 Ariño AH., Chavan VC., Fatih DP. 2013. Assessment of User Needs of Primary Biodiversity

294 Data: Analysis, Concerns and Challenges. Biodiversity Informatics 8:59-93. DOI:

295 http://dx.doi.org/10.17161/bi.v8i2.4094.

296 Ariño AH., Chavan V., Otegui J. 2016. Best Practice Guide for Data Gap Analysis for

297 Biodiversity Stakeholders. DOI: 10.13140/RG.2.2.14018.17608.

298 Avenant NL. 2005. Barn owl pellets: a useful tool for monitoring small mammal communities?

299 Belgian Journal of Zoology 135:39-43.

300 Beck J., Böller M., Erhardt A., Schwanghart W. 2014. Spatial bias in the GBIF database and its

301 effect on modeling species' geographic distributions. Ecological Informatics 19:10-15. DOI:

$302 \quad$ 10.1016/j.ecoinf.2013.11.002.

303 Boakes EH., McGowan PJK., Fuller RA., Chang-qing D., Clark NE., O’Connor K., Mace GM.

304 2010. Distorted Views of Biodiversity: Spatial and Temporal Bias in Species Occurrence 
Data. PLoS Biology 8:e1000385. DOI: 10.1371/journal.pbio.1000385.

306

307

308

309

310

311

312

313

314

315

316

317

318

319

320

321

322

323

324

325

326

327

Boero F., Kraberg AC., Krause G., Wiltshire KH. 2015. Time is an affliction: Why ecology cannot be as predictive as physics and why it needs time series. Journal of Sea Research 101:12-18. DOI: 10.1016/j.seares.2014.07.008.

Chapman AD. 2005. Principles of data quality, version 1.0. Copenhagen.

Cisneros LM., Fagan ME., Willig MR. 2015. Effects of human-modified landscapes on taxonomic, functional and phylogenetic dimensions of bat biodiversity. Diversity and Distributions 21:523-533. DOI: 10.1111/ddi.12277.

Crowl TA., Crist TO., Parmenter RR., Belovsky G., Lugo AE. 2008. The spread of invasive species and infectious disease as drivers of ecosystem change. Frontiers in Ecology and the Environment 6:238-246. DOI: 10.1890/070151.

Dorresteijn I., Teixeira L., von Wehrden H., Loos J., Hanspach J., Stein JAR., Fischer J. 2015. Impact of land cover homogenization on the Corncrake (Crex crex) in traditional farmland. Landscape Ecology 30:1483-1495. DOI: 10.1007/s10980-015-0203-7.

Ellis EC., Klein Goldewijk K., Siebert S., Lightman D., Ramankutty N. 2010. Anthropogenic transformation of the biomes, 1700 to 2000. Global Ecology and Biogeography 19:589-606. DOI: $10.1111 / \mathrm{j} .1466-8238.2010 .00540 . x$.

Escala C., Irurzun JC., Rueda A., Ariño AH. 1997. Atlas de los Insectívoros y Roedores de Navarra. Análisis biogeográfico.

Escribano N., Galicia D., Ariño AH., Escala C. 2016. Long-term data set of small mammals from owl pellets in the Atlantic-Mediterranean transition area. Scientific Data 3:160085. DOI: $10.1038 /$ sdata.2016.85.

ESRI. 2015. ArcGIS deskopt 10.0. 
328 Faith D., Collen B., Ariño A., Patricia Koleff PK., Guinotte J., Kerr J., Chavan V. 2013.

329 Bridging the biodiversity data gaps: Recommendations to meet users' data needs.

330 Biodiversity Informatics 8:41-58. DOI: 10.17161/bi.v8i2.4126.

331 Feranec J., Jaffrain G., Soukup T., Hazeu G. 2010. Determining changes and flows in European 332 landscapes 1990-2000 using CORINE land cover data. Applied Geography 30:19-35. DOI: $333 \quad$ 10.1016/j.apgeog.2009.07.003.

334 Ficetola GF., Rondinini C., Bonardi A., Katariya V., Padoa-Schioppa E., Angulo A. 2014. An 335 evaluation of the robustness of global amphibian range maps. Journal of Biogeography 336 41:211-221. DOI: 10.1111/jbi.12206.

337

Garrido-García JA., Rosário IT., Gisbert J., García-Perea R., Isabel A., López-Alabau A., Mathias L., Mira A., Santos SM., Sendra-Pérez I., Vicente V., Soriguer RC. 2013. Revisión a nivel ibérico de la distribución del topillo de Cabrera o iberón, Iberomys cabrerae (Thomas, 1906). Galemys 25:35-49. DOI: 10.7325/Galemys.2013.A4.

Gobierno de Navarra. 2000. Plan Forestal de Navarra.

Hermoso V., Kennard MJ., Linke S. 2013. Data Acquisition for Conservation Assessments: Is the Effort Worth It? PLoS ONE 8:e59662. DOI: 10.1371/journal.pone.0059662.

Hill AW., Otegui J., Ariño AH., Guralnick RP. 2010. GBIF Position Paper on Future Directions and Recommendations for Enhancing Fitness-for-Use Across the GBIF Network, version 1.0. Copenhagen.

Isaac NJB., Pocock MJO. 2015. Bias and information in biological records. Biological Journal of the Linnean Society 115:522-531. DOI: 10.1111/bij.12517/abstract.

Martínez JA., Zuberogoitia I. 2004. Habitat preferences and causes of population decline for Barn owls Tyto alba: a multi-scale approach. Ardeola 51:303-317. 
351 Moscoso V., Albernaz AL., Salomão RDP. 2013. Niche modelling for twelve plant species (six

352 timber species and six palm trees) in the Amazon region, using collection and field survey data. Forest Ecology and Management 310:652-662. DOI: 10.1016/j.foreco.2013.08.064.

354

355

356

357

358

359

360

361

362

363

364

365

366

367

368

369

370

371

372

373

Ngai JT., Kirby KR., Gilbert B., Starzomski BM., Pelletier AJD., Conner JCR. 2008. The impact of land-use change on larval insect communities: Testing the role of habitat elements in conservation. Ecoscience 15:160-168. DOI: 10.2980/15-2-3098.

Nogués-Bravo D. 2006. Assessing the effect of environmental and anthropogenic factors on land-cover diversity in a Mediterranean mountain environment. Area 38:432-444. DOI: 10.1111/j.1475-4762.2006.00709.x.

Nori J., Lemes P., Urbina-Cardona N., Baldo D., Lescano J., Loyola R. 2015. Amphibian conservation, land-use changes and protected areas: A global overview. Biological Conservation 191:367-374. DOI: 10.1016/j.biocon.2015.07.028.

Otegui J., Ariño AH., Chavan V., Gaiji S. 2013. On the dates of the GBIF mobilised primary biodiversity data records. Biodiversity Informatics 8:173-184.

De Palma A., Kuhlmann M., Roberts SPM., Potts SG., Börger L., Hudson LN., Lysenko I., Newbold T., Purvis A. 2015. Ecological traits affect the sensitivity of bees to land-use pressures in European agricultural landscapes. Journal of Applied Ecology 52:1567-1577. DOI: $10.1111 / 1365-2664.12524$.

Palomo LJ., Gisbert J., Blanco JC. 2007. Atlas y libro rojo de los mamíferos terrestres de España. Madrid: Dirección General para la Biodiversidad-SECEM-SECEMU.

Pimm SL. 1991. The balance of nature?: ecological issues in the conservation of species and communities. London: The University of Chicago Press.

Powney GD., Isaac NJB. 2015. Beyond maps: a review of the applications of biological records. 
Rittenhouse CD., Pidgeon AM., Albright TP., Culbert PD., Clayton MK., Flather CH., Masek JG., Radeloff VC. 2012. Land-Cover Change and Avian Diversity in the Conterminous United States. Conservation Biology 26:821-829. DOI: 10.1111/j.1523-1739.2012.01867.x.

378

Rocchini D., Hortal J., Lengyel S., Lobo JM., Jimenez-Valverde A., Ricotta C., Bacaro G., Chiarucci A. 2011. Accounting for uncertainty when mapping species distributions: The need for maps of ignorance. Progress in Physical Geography 35:211-226. DOI: 10.1177/0309133311399491.

Sala OE., Chapin FS., Armesto JJ., Berlow E., Bloomfield J., Dirzo R., Huber-Sanwald E., Huenneje LF., Jackson RB., Kinzig A., Leemans R., Lodge DM., Mooney HA., Oesterheld M., LeRoy Poff N., Sykes MT., Walker BH., Walker M., Wall DH. 2000. Global Biodiversity Scenarios for the Year 2100. Science 287:1770-1774. DOI: 10.1126/science.287.5459.1770.

Sánchez-Fernández D., Lobo JM., Abellán P., Millán A. 2011. How to identify future sampling areas when information is biased and scarce: An example using predictive models for species richness of Iberian water beetles. Journal for Nature Conservation 19:54-59. DOI: 10.1016/j.jnc.2010.05.003.

Sastre P., Lobo JM. 2009. Taxonomist survey biases and the unveiling of biodiversity patterns. Biological Conservation 142:462-467. DOI: 10.1016/j.biocon.2008.11.002.

Sieber A., Uvarov N V., Baskin LM., Radeloff VC., Bateman BL., Pankov AB., Kuemmerle T. 2015. Post-Soviet land-use change effects on large mammals' habitat in European Russia. Biological Conservation 191:567-576. DOI: 10.1016/j.biocon.2015.07.041.

Torre I., Gracia-Quintas L., Arrizabalaga A., Baucells J., Díaz M. 2015. Are recent changes in 
397 the terrestrial small mammal communities related to land use change? A test using pellet 398 analyses. Ecological Research 30:813-819. DOI: 10.1007/s11284-015-1279-x.

399 Torre I., Arrizabalaga A., Flaquer C. 2004. Three methods for assessing richness and 400 composition of small mammal communities. Journal of Mammalogy 85:524-530.

401 Wagner KD., Krauss J., Steffan-Dewenter I. 2013. Butterfly diversity and historical land cover 402 change along an altitudinal gradient. Journal of Insect Conservation 17:1039-1046. DOI: $403 \quad 10.1007 / \mathrm{s} 10841-013-9587-3$.

404 Willis KJ., Araujo MB., Bennett KD., Figueroa-Rangel B., Froyd CA., Myers N. 2007. How can 405 a knowledge of the past help to conserve the future? Biodiversity conservation and the 406 relevance of long-term ecological studies. Philosophical Transactions of the Royal Society 407 B: Biological Sciences 362:175-187. DOI: 10.1098/rstb.2006.1977. 


\section{Figure 1 (on next page)}

Sampling sites for small mammals in the 'Pellet sampling' dataset in Navarra.

Inset: Location of Navarra within the Iberian Peninsula. Outset: Navarra in white line. 
PeerJ

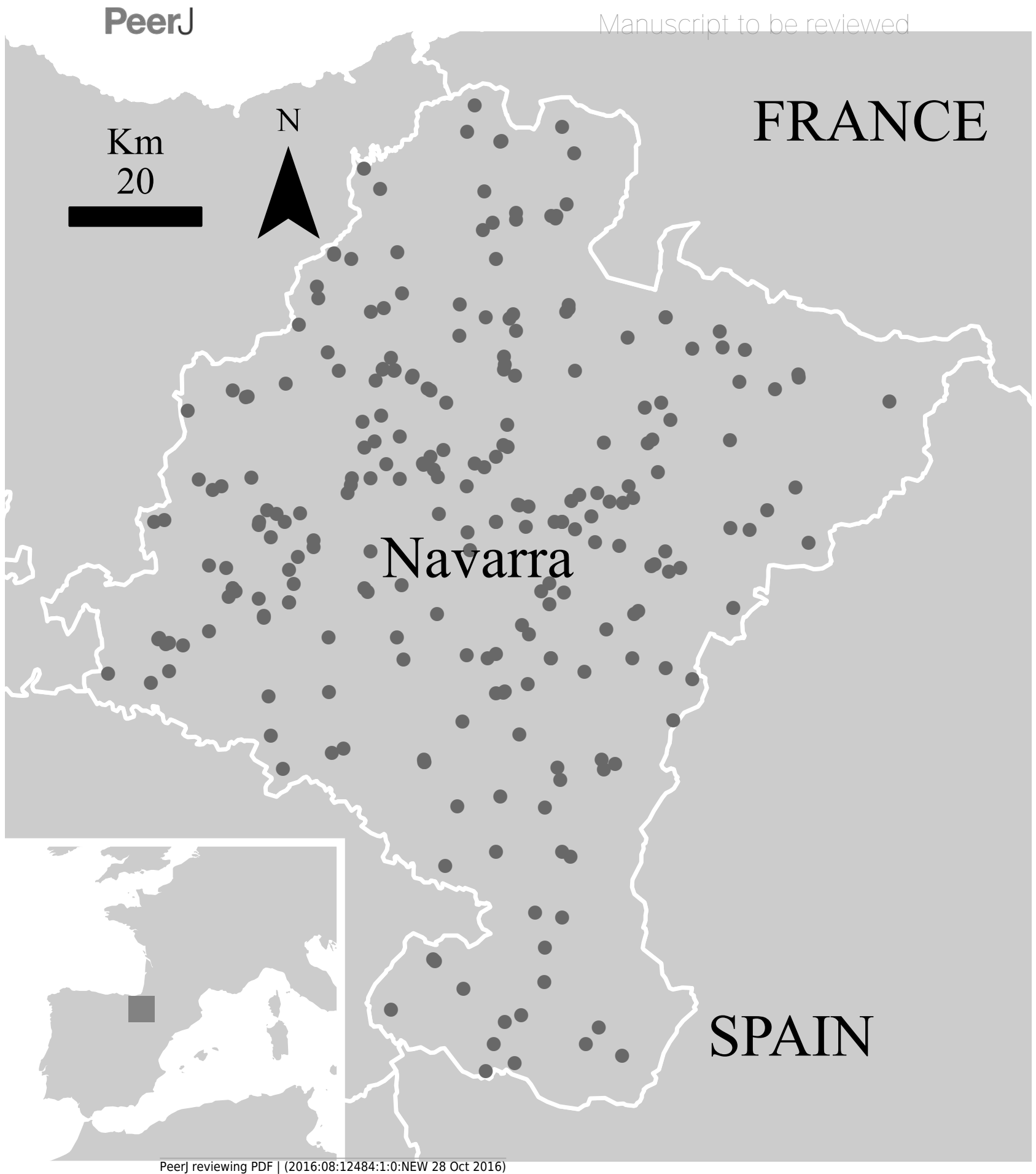


Figure 2 (on next page)

Temporal and spatial distribution of records in 'pellet sampling' dataset.

(A) Temporal distribution of the records. Bars: historical registry of small mammals in Navarra (as number of records per year). Line: species accumulation curve. (B) Distribution of records according to the three time intervals. Dark blue: cells first sampled in the time interval considered. Light blue: cells already sampled before the interval. 


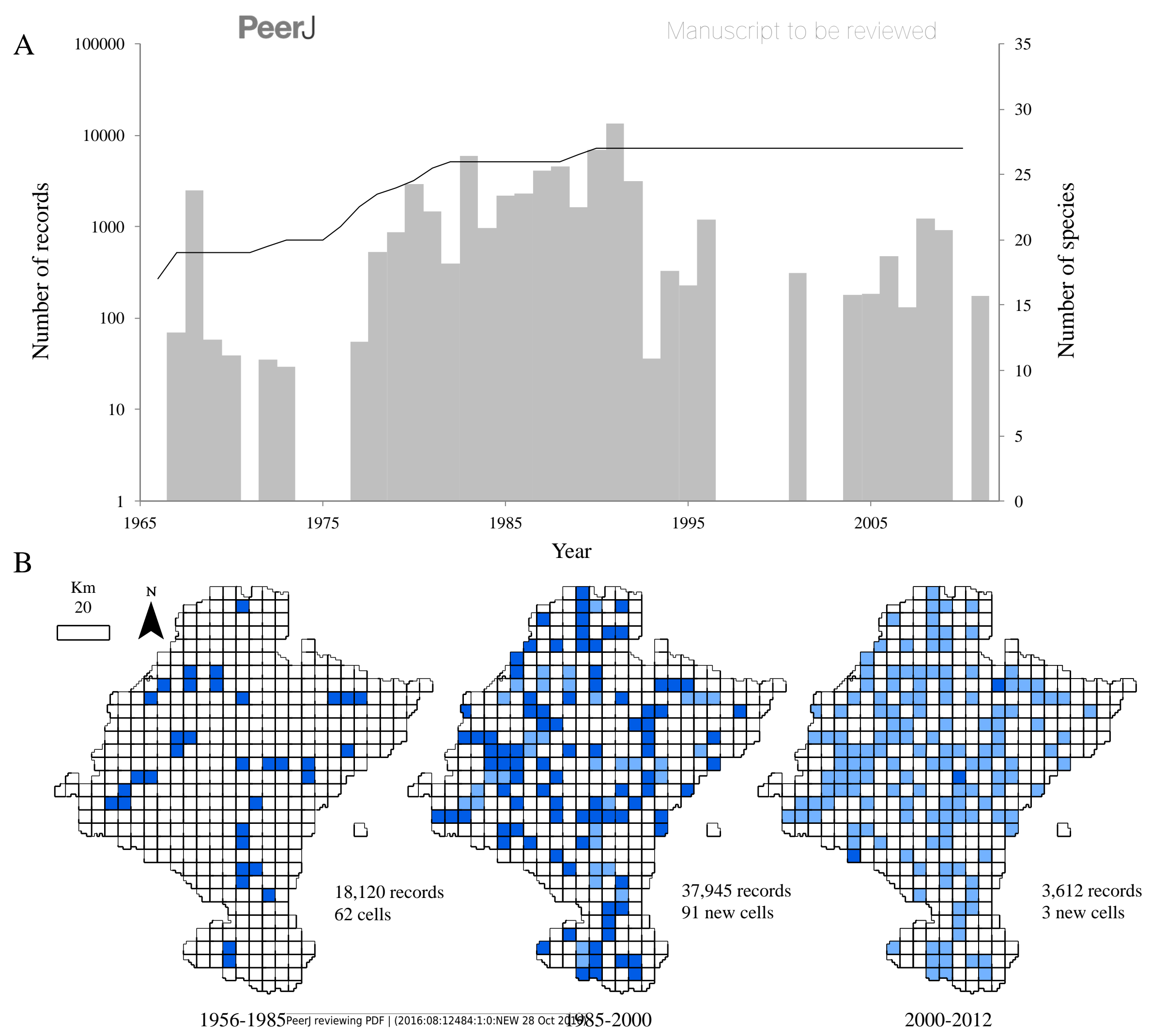




\section{Figure 3 (on next page)}

Distribution of cells holding small mammals' records.

White: cells with no data; brown: cells with obsolete data; blue: cells with non-obsolete data. Blue shades: length of time since the cell was last visited (darker: more recent visit). 


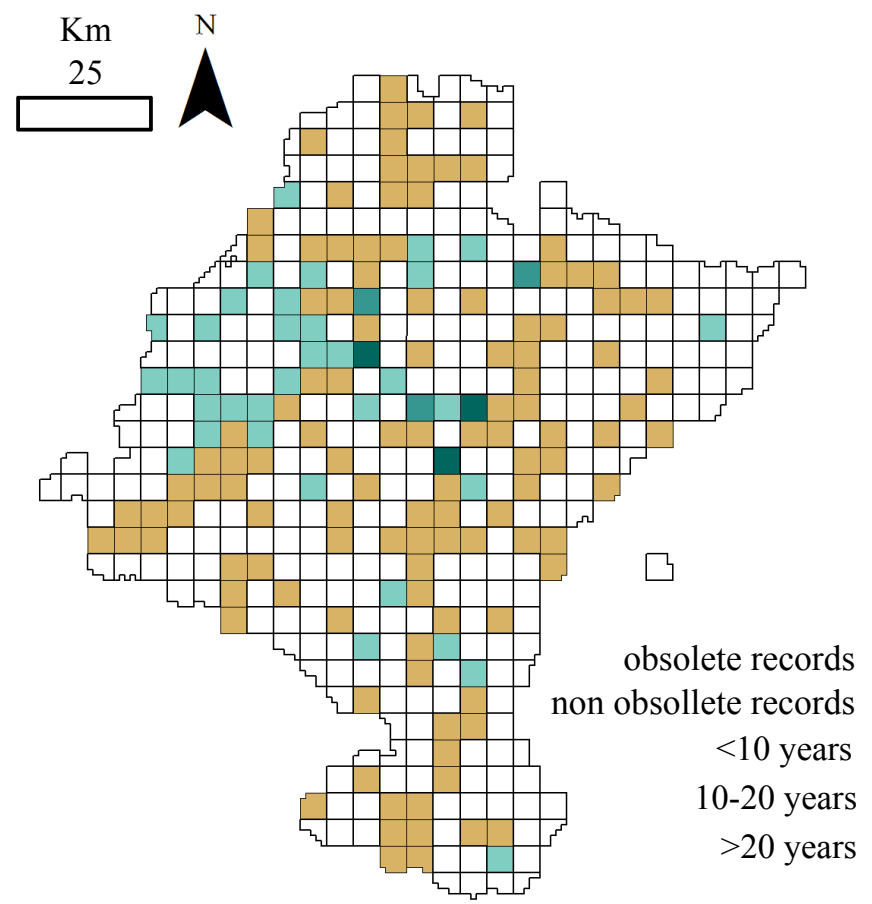


Figure 4 (on next page)

Relationship between the percentage of records loss by species and the number of records gathered in the entire dataset (log scale). 



\section{Table $\mathbf{1}$ (on next page)}

Overview of information contained in the dataset considering (a) all samples and (b) samples staying not compromised by land use changes. 


\begin{tabular}{|c|c|c|c|c|}
\hline \multirow[b]{2}{*}{ Species } & \multicolumn{2}{|l|}{ (a) Entire dataset } & \multicolumn{2}{|c|}{ (b) Non obsolete records } \\
\hline & $\begin{array}{l}\text { Records } \\
\text { (count) }\end{array}$ & $\begin{array}{l}\text { Cells } \\
\text { (count) }\end{array}$ & Records (count) & $\begin{array}{l}\text { Cells } \\
\text { (count) }\end{array}$ \\
\hline Apodemus flavicollis & 541 & 43 & 177 & 16 \\
\hline Apodemus sylvaticus & 9,837 & 148 & 2,607 & 45 \\
\hline Arvicola sapidus & 152 & 47 & 27 & 15 \\
\hline Arvicola terrestris & 166 & 8 & 37 & 2 \\
\hline Crocidura russula & 14,585 & 146 & 3,929 & 45 \\
\hline Crocidura suaveolens & 33 & 8 & & \\
\hline Eliomys quercinus & 27 & 14 & 1 & 1 \\
\hline Glis glis & 4 & 3 & 3 & 2 \\
\hline Micromys minutus & 62 & 13 & 16 & 4 \\
\hline Microtus agrestis & 3,459 & 113 & 1,205 & 42 \\
\hline Microtus arvalis & 491 & 12 & 86 & 3 \\
\hline Microtus cabrerae & 2 & 1 & & \\
\hline Microtus duodecimcostatus & 7,983 & 135 & 2,092 & 45 \\
\hline Microtus gerbei & 1,353 & 89 & 484 & 37 \\
\hline Microtus lusitanicus & 2,598 & 54 & 226 & 21 \\
\hline Mus domesticus & 815 & 82 & 212 & 24 \\
\hline Mus spretus & 11,734 & 123 & 2,238 & 39 \\
\hline Myodes glareolus & 326 & 48 & 110 & 21 \\
\hline Neomys anomalus & 30 & 19 & 12 & 8 \\
\hline Neomys fodiens & 302 & 48 & 93 & 20 \\
\hline Rattus norvegicus & 102 & 38 & 13 & 7 \\
\hline Rattus rattus & 17 & 12 & 4 & 3 \\
\hline Sorex araneus & 2 & 1 & & \\
\hline Sorex coronatus & 3,573 & 94 & 789 & 37 \\
\hline Sorex minutus & 552 & 54 & 88 & 25 \\
\hline Suncus etruscus & 913 & 91 & 77 & 20 \\
\hline Talpa europaea & 18 & 8 & 2 & 2 \\
\hline & 59,677 & & 14,528 & \\
\hline
\end{tabular}

1 